\title{
Modelling and simulation of a heat pump for simultaneous heating and cooling
}

\author{
Paul Byrne ${ }^{1 *}$, Jacques Miriel ${ }^{1}$, Yves Lénat ${ }^{1}$
}

(1) Equipe MTRhéo, Laboratoire LGCGM, INSA Rennes - Université de Rennes1, France

*Corresponding author:

paul.byrne@univ-rennes1.fr

Postal address:

IUT Génie Civil

3 rue du clos Courtel

BP 90422

35704 Rennes Cedex 7

France

Tel: +33223234297

Fax: +332232340 51 


\section{ABSTRACT}

The heat pump for simultaneous heating and cooling (HPS) carries out space heating, space cooling and hot water production for small office and residential buildings. It works under heating, cooling and simultaneous modes to produce hot and chilled water according to the thermal demand of the building. A subcooler connected to a water tank is placed after the condenser to recover some energy by subcooling of the refrigerant during a heating mode. The water loop at a higher temperature than ambient air is used subsequently as a source for a water evaporator. Average winter performance is improved compared to a standard reversible heat pump (HP). The air evaporator is defrosted by a two-phase thermosiphon without stopping the heat production. The operation of the HPS is modelled using TRNSYS software. The model is validated using results of an experimental study carried out on a HPS prototype working with R407C. Annual simulations of the HPS coupled to a hotel are run in order to evaluate annual performance and energy consumption of the system. The results are compared to the ones of a standard reversible HP. Depending on the scenario, savings in electric energy consumption and annual performance improvement can reach respectively 55\% and $19 \%$.

Keywords: heat pump, simultaneous heating and cooling, defrosting

\section{INTRODUCTION}

In developed countries, commercial and residential buildings account for around $40 \%$ of national energy consumption and $25 \%$ of greenhouse gas emissions. This is the sector in which savings have to be made in priority. Thermal performance of buildings is thus continuously improving thanks to thermal regulations. Besides, comfort requirements demand more and more energy. Whilst domestic hot water (DHW) demands increase continuously, a demand for cooling appears or rises to compensate internal heat gains caused by more and more household electrical equipment. A more insulated thermal envelope implies also that new buildings need less energy for heating and more for cooling. Therefore thermal needs of new buildings are more balanced between heating and cooling over the year.

During winter, energy is demanded exclusively for space heating and DHW production. Between winter and summer, some buildings can demand simultaneously cooling in rooms facing south and heating in rooms facing north. During summer, energy is needed for DHW production and space cooling at the same time. An answer to a dual energy demand is the heat pump, since it supplies simultaneously a heating capacity at the condenser and a cooling capacity at the evaporator. Annex 48 of the ECBCS programme (Energy Conservation in and Community Systems) of the IEA (International Energy Agency) deals with this topic (Stabat, 2008). The annex first highlights that some buildings actually present simultaneous or slightly delayed heating and cooling needs and then proposes solutions to satisfy these needs using heat pumping technology.

This study presents the model of a heat pump that can satisfy fluctuating needs, simultaneous or not, in heating and cooling. This heat pump is named HPS (Heat Pump for Simultaneous heating and cooling) and can be installed in hotels where DHW demands are high and glassfronted buildings where simultaneous needs in space heating and space cooling are more frequent. The first objective is to produce, as often as possible, heat and cold using the same energy input at the compressor. The second objective is to limit the performance loss of airsource heat pumps during winter due to low air temperatures and frosting (Liu et al., 2007). A previous publication on the modelling and simulation of the HPS using HFC or $\mathrm{CO}_{2}$ as a working fluid was carried out (Byrne et al., 2009). In the present study focusing only on $\mathrm{R} 407 \mathrm{C}$, the models chosen are not highly-efficient ones (like in the previous publication) but 
real ones, validated by experimental data. Two other articles were published on the HPS prototype description and the experimental study (Byrne et al., 2011a and 2011b).

The most recent modelling techniques are reviewed by Ding (2007). This article states that the compressor model should precisely calculate input power, refrigerant mass flow rate and discharge temperature and that multi-node heat exchanger models divided into zones are accurate enough for dynamic modelling of refrigeration systems. Numerous publications can be found in the literature on more or less detailed compressor modelling (Blunier et al. 2009) (Cuevas and Lebrun, 2009) (Cuevas et al. 2010) (Duprez et al. 2007) (Duprez et al. 2010) (Negrao et al. 2011) (Tseng et al. 2006) (Winandy et al. 2002) (Winandy and Lebrun, 2002) (Sun et al. 2010). Heat exchanger modelling methods can be found in the ASHRAE Handbook Fundamentals (ASHRAE, 2001).

Bourke and Bansal (2010) coupled an air-source heat pump water heater to domestic hot water consumptions using TRNSYS software (Solar Energy Laboratory, 2000). Kinab et al. (2010) also used this software to model and simulate a reversible heat pump including detailed compressor, heat exchangers and frosting/defrosting model. In this article, the components of the HPS model are programmed in FORTRAN and adapted to the draft of TRNSYS models. They are assembled to form a global model of heat pump in the TRNSYS Simulation Studio and coupled to models of water tanks, themselves coupled to a building model. The heat pump model is validated by results of experiments carried out on a R407C HPS prototype. Finally, annual simulations are run using three weather data files to evaluate the performance of a HPS, which is compared to the one of a standard reversible heat pump.

\section{HPS CONCEPT}

\subsection{Refrigeration circuit}

The HPS prototype (figure 1) produces hot and chilled water using plate heat exchangers. Performance verification of this prototype can be found in a previous publication (Byrne et al. 2011a).

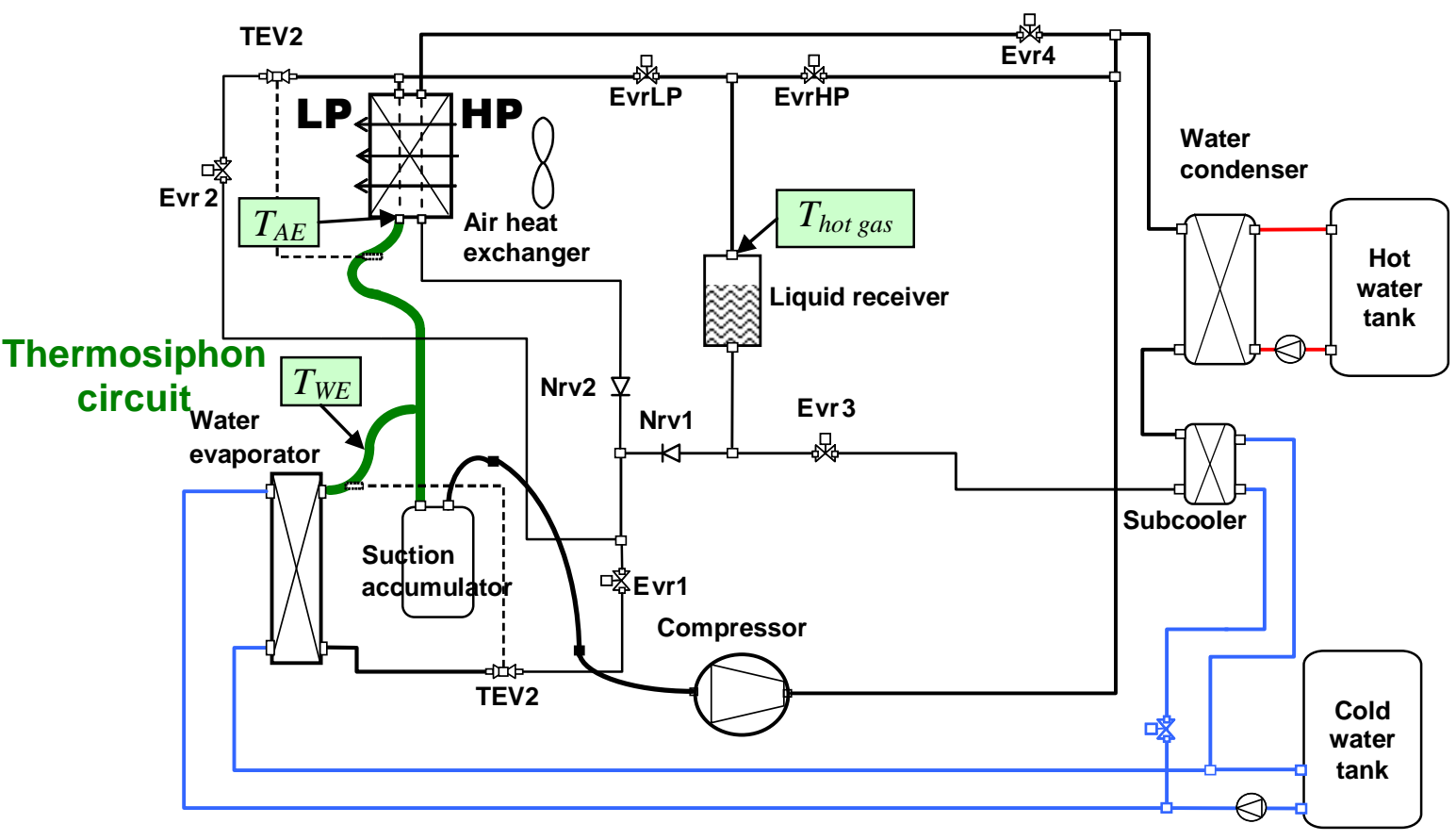

Figure 1: HPS refrigerant circuit 
A balancing air coil (figure 2) works either as a condenser for heat rejection in a cooling mode or as an evaporator for heat suction in a heating mode, using two separate and alternated circuits of refrigerant. The air evaporator and the air condenser are never used at the same time. These functions have been assembled in the same three-fluid air coil (air, high pressure refrigerant and low pressure refrigerant) in order to decrease the finned surface area compared to separate air condenser and evaporator. When the tubes of the air evaporator are used, the surface of the fins near the tubes of the air condenser is also used for the air evaporator and vice versa.

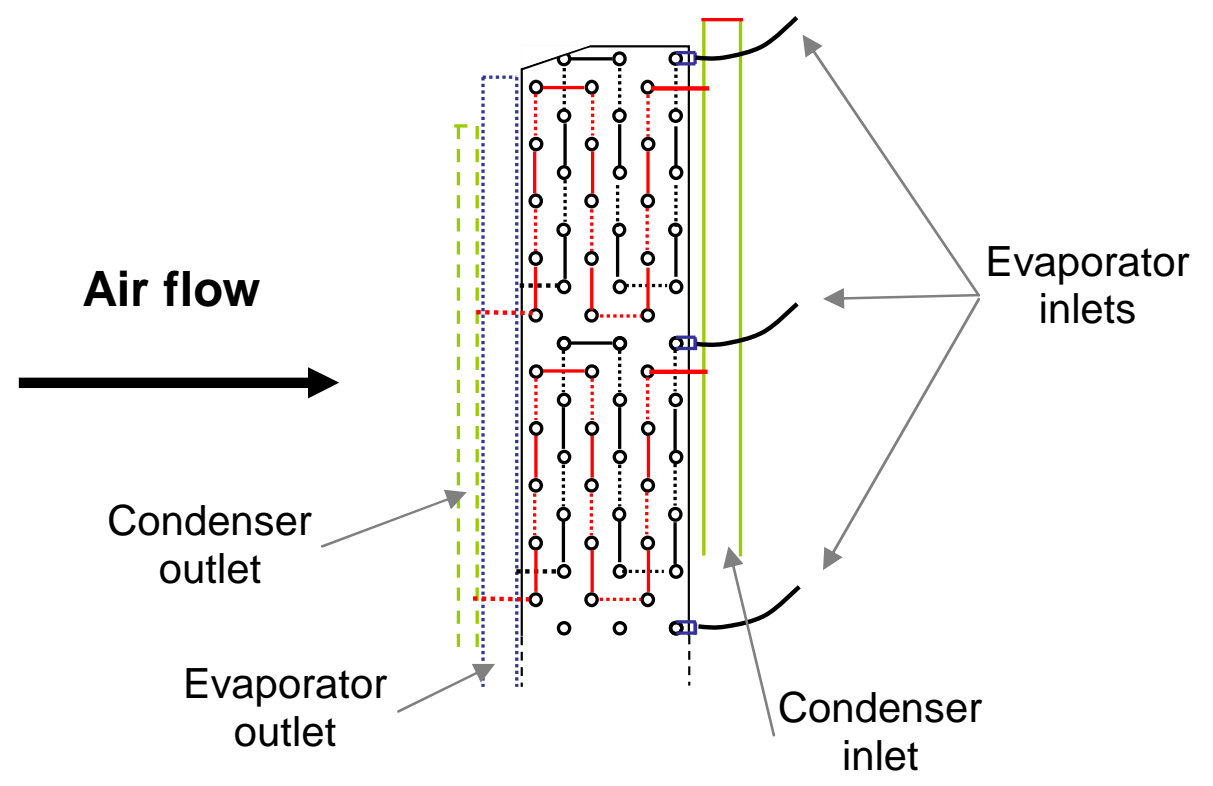

Figure 2: Schematic side view of the three-fluid air heat exchanger

A plate heat exchanger is placed after the water condenser to recover the subcooling energy of the refrigerant in the cold water tank. This amount of energy is a short-time heat storage that will be used subsequently to carry out the evaporation on a water source during winter sequences.

Depending on the mode of operation, the electric components (compressor, fan and electronic valves named Evr) are managed automatically by a programmable controller or by an action of the operator on the control computer. The thermostatic expansion valves are named TEV1 (connected to the water evaporator) and TEV2 (connected to the air evaporator). Non-return valves named Nrv1 and Nrv2 are placed at the outlets of the air and water condensers to avoid refrigerant trapping in the condensers. Table 1 shows the general specifications of the components of the prototype.

Table 1: Specifications of HPS components

\begin{tabular}{|c|c|}
\hline Component & Specification \\
\hline Compressor & Swept volume: $14.5 \mathrm{~m}^{3} / \mathrm{h}$ \\
Brand: Copeland & Nominal cooling capacity \\
Type: Scroll & $\left(\right.$ Tev $\left.=0^{\circ} \mathrm{C} / \mathrm{Tcd}=40^{\circ} \mathrm{C}\right):$ \\
Ref: ZB38KCE-TFD & $11.5 \mathrm{~kW}$ \\
\hline Water heat exchangers & Type: plate heat exchanger \\
condenser & 50 plates, $2.45 \mathrm{~m}^{2}$ \\
evaporator & 34 plates, $0.8 \mathrm{~m}^{2}$ \\
subcooler & 14 plates, $0.16 \mathrm{~m}^{2}$ \\
\hline Air heat exchangers & Type: finned tubes, $68 \mathrm{~m}^{2}$ \\
& 6 rows of 30 tubes \\
& $(\mathrm{I}=750 \mathrm{~mm}, \varnothing=10 \mathrm{~mm})$ \\
\hline Working fluid & R407C \\
\hline
\end{tabular}




\subsection{High pressure control}

As pressures and temperatures are linked during condensation, a high pressure control system ensures that condensation is completed in the condenser (and does not finish in the subcooler). Moreover it is able to control the condensation temperature and thus the heating capacity. A special liquid receiver is placed on the liquid line. It is connected to the compressor discharge line and the inlet of the air evaporator by copper tubes of smaller diameter on which electronic on-off valves are placed (EvrHP and EvrLP in figure 1). The high pressure control system indirectly controls the volume of liquid in the receiver. The volume of liquid in the different condensers depends on the mode. If the high pressure is below the set point, the electronic valve EvrHP is opened by the controller. The receiver is filled up with gas coming from the compressor discharge line at a pressure higher than the pressure in the receiver until the set pressure is reached. The gas entering the receiver drives the liquid towards the evaporator. The non-return valve closes because pressure becomes higher at its outlet than at its inlet. The subcooling heat exchanger and the bottom part of the water condenser are filled up with more liquid until the appropriate level of liquid is reached. If however the chosen mode is the cooling mode, the condenser becomes the air heat exchanger. The set point for pressure is then the lowest possible. The pressure is reduced by driving the vapour out of the top part of the receiver towards the inlet of the air evaporator. The refrigerant in a liquid phase is sucked out of the water condenser and the subcooler and enters the receiver. The operation of the control system depends upon a special liquid receiver being designed sufficiently high and narrow with the main objective to enhance temperature stratification and to limit as much as possible thermal transfer between the gas and the liquid. When the gas is injected, part of it condenses. When gas is rejected to the low pressure, part of the liquid evaporates. Although these phenomena can reduce the efficiency of the liquid variation process in the receiver, it stabilizes the control system. The receiver is also thermally insulated to reduce the heat transfer towards the ambience.

\subsection{Operating modes}

Three operating modes can be run.

- The simultaneous mode produces hot and cold water using the water condenser and the water evaporator (electronic valves Evr1 and Evr3 are open).

- The heating mode produces hot water using the water condenser, the air evaporator (electronic valves Evr2 and Evr3 are open) and also uses the subcooler to store the subcooling energy in the cold water tank.

- The cooling mode only produces cold water using the water evaporator and the air condenser (electronic valves Evr1 and Evr4 are open).

The variables used to activate the mode of operation are the temperatures of water entering the water condenser and the water evaporator. Every simulation time step, the values are compared to set points using on/off differential controllers with hysteresis. The controllers deliver a signal at 1 if heating and/or cooling is needed. The corresponding operating mode, heating only, cooling only or simultaneous mode is consequently activated.

\subsection{Summer sequence}

During summer, the needs are usually higher in cooling than in heating. Some needs in heating can be observed for DHW production. The sequence alternates between cooling and simultaneous modes depending on the water temperatures. 


\subsection{Classic winter sequence}

During winter, the sequence alternates between heating and simultaneous modes. The cold water tank is used as a short-time heat storage. The sequence begins by the heating mode engaging the water condenser, the air evaporator and the subcooler. The hot water tank is heated by water circulating through the condenser. Meanwhile, the cold water tank is heated, usually from 5 to $15^{\circ} \mathrm{C}$, by the refrigerant subcooling energy. Then the HPS switches to the simultaneous mode and uses energy stored in the cold water tank as a heat source for the water evaporator. The cold water tank temperature decreases from 15 to $5^{\circ} \mathrm{C}$.

In the simultaneous mode, the evaporating temperature is higher than in the heating mode from the moment that ambient air is colder than the short-time heat storage tank.

Therefore, using the simultaneous mode for a time during the winter sequence enables to produce hot water continuously with improved average system performance compared to standard air-source heat pumps. Besides, in the simultaneous mode, the air evaporator is not used for evaporation and can be defrosted using a two-phase thermosiphon.

\subsection{Winter sequence with defrosting}

In the heating mode, under cold outside air temperatures, the fins of the air evaporator get frosted. Before frost thickness becomes critical, the cold tank temperature rises to $15^{\circ} \mathrm{C}$ and the simultaneous mode is switched on by the controller. In this mode, the air coil is inactive and automatically defrosted by a two-phase thermosiphon formed between the two evaporators. Evaporation is carried out using the water source at a higher temperature than ambient air. Inside the air coil, the inner surface temperature of the tubes is at a low temperature because of the frost layer that has grown on the fins during the heating mode (previously running). Refrigerant in a vapour phase surrounding the low temperature surface condenses and flows down to the water evaporator by gravity. The condensation energy is transferred to the frost layer which actually melts. In addition to the regular flow of vapour generated at the evaporator and sucked by the compressor, a supplementary flow of vapour is created by the pressure difference. This amount of vapour flows to the condenser of the thermosiphon to occupy the volume difference created by condensation of the refrigerant. The phenomenon ends when the temperature and pressure differences disappear, thus when the evaporator is completely defrosted. A major advantage of this sequence is to carry out defrosting without stopping the heat production. Frost thickness can thus be minimized and mean convection heat transfer coefficients at the air evaporator can be maximized. The average heat pump efficiency under frosting conditions is improved compared to standard airsource heat pumps that use hot gas or reversed cycle defrosting methods (Huang et al., 2009). This defrosting method was tested in laboratory. Methods and results can be found in a previous publication (Byrne et al. 2011b).

\section{MODELLING}

\subsection{Simulation tool}

The numerical study is carried out under the TRNSYS environment. The scheme of the simulation model is shown in figure 3 . The heat pump model and the building are linked by a system for thermal energy storage and distribution composed of water tanks, a tap water temperature calculator, a consumption profile generator and an auxiliary heater. The simulation time step is 5 minutes.

A preliminary study is made to calculate the steady state thermal capacities and electric power of the HPS, for each mode and for a wide range of water and air temperatures (paragraph 4.4). 
Every component of the machine is a homemade model programmed in FORTRAN. The refrigeration device is modelled as the connection of the different components using the input and output variables. These simulations result in tables of thermal capacities and electric power depending on source temperatures (appendixes 1 and 2).

In the final simulation model, these tables are read by type42a "conditioning equipment with 3 independent variables" (shown in figure 3 ) available in the TRNSYS model library. The 3 independent variables are the heat source temperature, the heat sink temperature and the operating mode. The operating mode is given by the regulation model depending on the water tank temperatures. TRNBuild is used to obtain a multizone building model. The output variables are the heating and cooling demands. The DHW demand is given by a consumption profile provided by the French organization CSTB for an implementation in the TRNSYS model library.

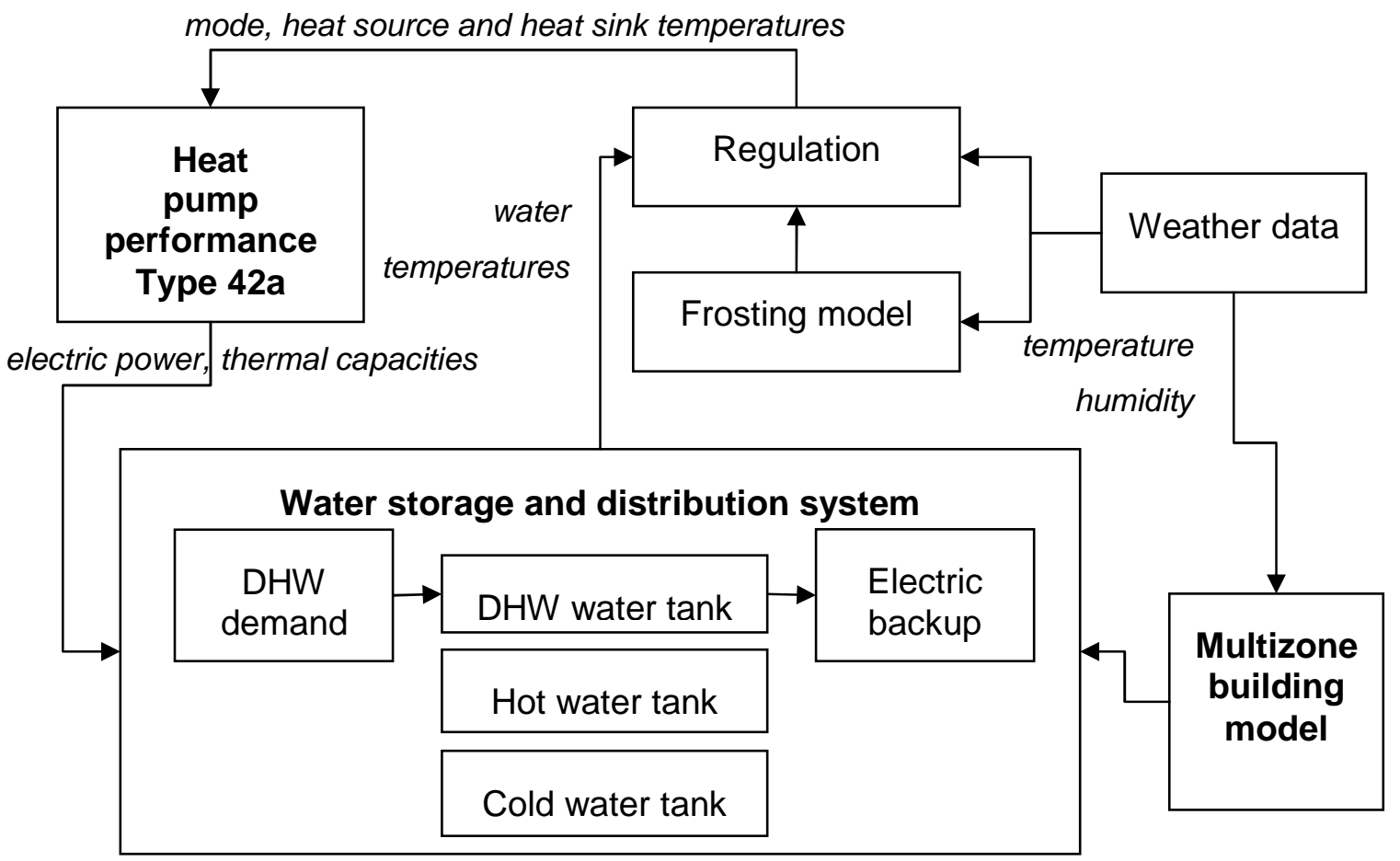

Figure 3: Scheme of the simulation model of the heat pump coupled to the building

\subsection{Building description}

A hotel of 45 bedrooms is modelled. Figure 4 shows a 3D-view of the building on which it can be noticed that the reception area outside wall is fully glazed and that the dining room has an outside wall oriented towards the West. Thermal zones, wall materials, glazed surfaces, solar protections and ventilation, occupancy and lighting schedules are defined using the building module of TRNSYS in accordance with the French thermal regulation RT 2005. The model calculates the thermal need of the hotel in heating and cooling. Energy for domestic hot water production is given by the water consumption depending on a daily profile, multiplied by the specific heat of water and the temperature difference between the set temperature of $50^{\circ} \mathrm{C}$ and the cold water network temperature. This simulation is run using the weather data file of three sites with different climates: Rennes (mild oceanic climate), Brussels (colder oceanic climate) and Marseille (Mediterranean). 


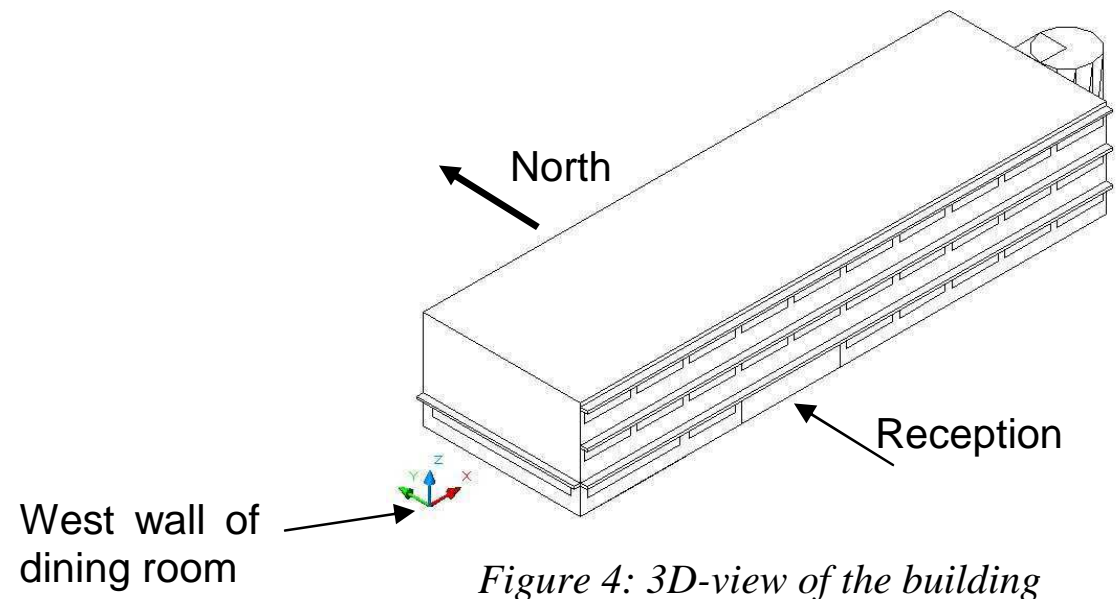

\subsection{Control strategy}

In the final simulations using the environment described in paragraph 4.1, the regulation model defines the operating mode depending on the water temperatures. The cold water set point for temperature is $9^{\circ} \mathrm{C}$ with upper and lower dead bands of $2^{\circ} \mathrm{C}$ as shown in figure 5 . The set point temperature for hot water is given by the heating curve presented in figure 6 . The differential is $\pm 2.5^{\circ} \mathrm{C}$. For example, at an ambient temperature of $0^{\circ} \mathrm{C}$, the control signal that indicates a need in heating switches from 0 to 1 when the temperature of hot water entering the water condenser falls under $37.5^{\circ} \mathrm{C}$ and turns back to 0 when $42.5^{\circ} \mathrm{C}$ is reached. The DHW production control signal switches from 0 to 1 when the water temperature falls under $47.5^{\circ} \mathrm{C}$ and turns back to 0 when it reaches $52.5^{\circ} \mathrm{C}$. The standard heat pump does not produce DHW because this production is incompatible with cooling during the summer. In this case DHW production is carried out by a separate electric heater.

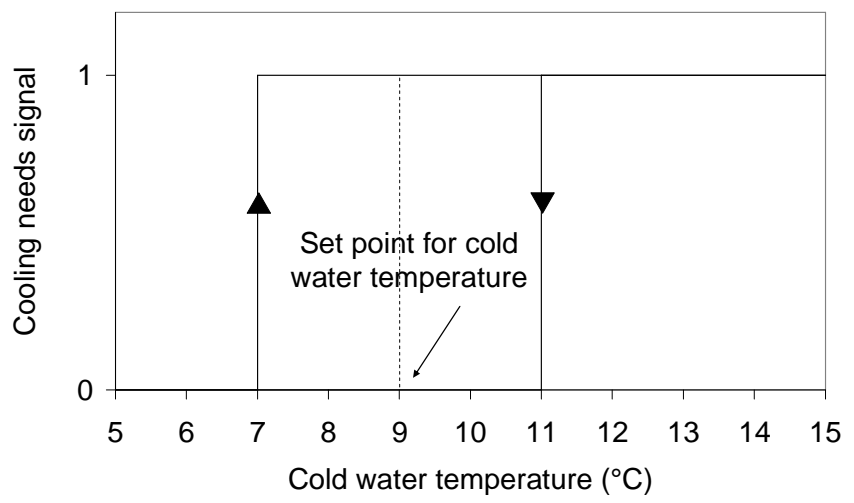

Figure 5: Control signal for cooling needs

A frosting model is applied to the standard reversible heat pump. This model calculates the frost thickness depending on the air mass flow rate, temperature and humidity. A clock launches a defrosting phase every 45 minutes if ambient temperature is below $7^{\circ} \mathrm{C}$. During a time step of 5 minutes, the cycle is reversed and the defrosting energy is provided by a condensation at the air heat exchanger. The defrosting energy is given by the frost mass and the latent heat of fusion. The corresponding cooling energy is provided by the hot water tank for space heating. This strategy simulates a break in the heat production and induces a loss of performance compared to a HPS. Thanks to the two-phase thermosiphon, defrosting of the HPS is carried out during a simultaneous mode. Therefore the frosting model is not applied to the HPS model. 


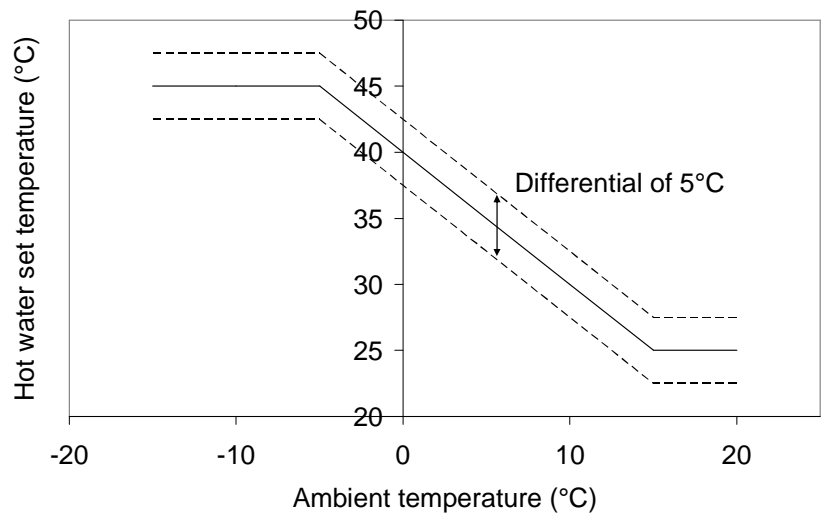

Figure 6: Set temperature for hot water depending on ambient temperature

\subsection{Detailed heat pump}

Three models corresponding to three operating modes (heating, cooling and simultaneous modes) were defined to calculate the steady state heating and cooling capacities and electric power. Pressure drops and heat losses to the environment are assumed negligible in heat exchangers.

The detailed heat pump modelling can be schemed following figure 7 . The models of compressor and heat exchangers are assembled depending on the operating mode. The dotted lines represent the fact that the subcooler is used only in the heating mode. Input temperatures are in grey $\left(T_{h s i}\right.$ : heat sink temperature; $T_{h s o}$ : heat source temperature, $T_{c w}$ : cold water temperature). Water and air mass flow rates are constants. The outputs are temperatures of hot or cold water production and electric power, cooling (subscript c), subcooling (subscript sc) and heating (subscript $\mathrm{h}$ ) capacities. A module standing for the high pressure control system calculates the high pressure in function of the inlet heat sink temperature.

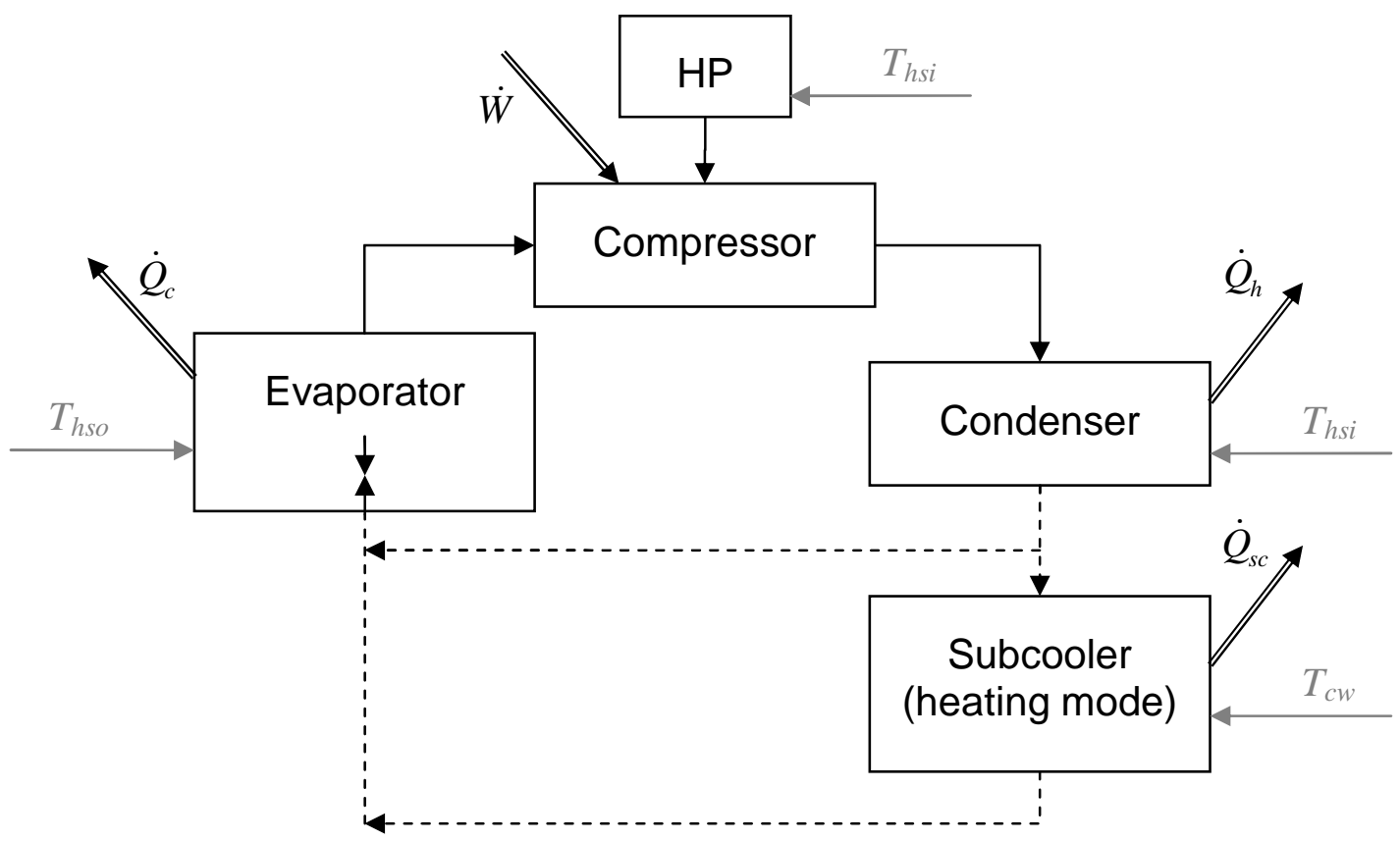

Figure 7: Scheme of the detailed heat pump modelling 


\subsubsection{Compressor}

The compressor model calculates the mass flow rate and the compression work knowing the input and output pressures (Equations 1 to 6) and using the Refprop database (2002). The volumetric efficiency (Equation 1) is calculated using a constant polytropic exponent of 1.076 for R407C. This value has been calculated using experimental results obtained in our laboratory on a Copeland ZB38KCE scroll compressor. A brief sensitivity analysis showed that a variation of \pm 0.1 of the polytropic exponent value would provoke a variation of the heating COP inferior to $1.4 \%$ on a range of pressure ratios from 1.5 to 5. Equation 1 comes from the theory of piston compressors. Thus the "relative clearance volume" $c$ becomes a "fictitious relative clearance volume" for scroll compressors. In this study, parameter $c$ is used as a fitting variable so that the modelling corresponds to the experiments.

The output pressure is assumed to be calculated by the high pressure control system in accordance with the hot water inlet temperature. The compressor efficiency for R407C is calculated using a correlation based on curve-fitted results of experiments carried out in our laboratory on the Copeland ZB38KCE compressor (Equation 2). The compressor efficiency was calculated using equation 6 knowing the enthalpy at suction and discharge of the compressor for a series of 97 experimental points. The average discrepancy between the model of equation 2 and the experimental points is $6 \%$ (maximum value 14\%). Finally, the discharge temperature is calculated thanks to the Refprop database for the outlet values of enthalpy (Equation 6) and high pressure.

$$
\begin{gathered}
\eta_{\text {vol }}=1-c \cdot\left[\left(\frac{H P}{L P}\right)^{\frac{1}{n}}-1\right] \\
\eta_{\text {comp }}=0.9962 \cdot \exp \left(-0.0565 \cdot \frac{H P}{B P}\right) \\
\dot{m}=\rho \cdot \eta_{\text {vol }} \cdot V_{s} \\
\dot{W}_{\text {carnot }}=\dot{m} \cdot\left(h_{o-\text { ideal }}-h_{i}\right) \\
\dot{W}=\frac{\dot{W}_{\text {Carnot }}}{\eta_{\text {comp }}} \\
h_{o}=h_{i}+\frac{h_{o-i d e a l}-h_{i}}{\eta_{\text {comp }}}
\end{gathered}
$$

\subsubsection{Heat exchangers}

The heat exchangers models use the Log Mean Temperature Difference (LMTD) method. The heat transfer coefficients and the steady state capacities are calculated using the geometrical characteristics of existing heat exchangers (Table 1), the McAdams correlations described in the ASHRAE Handbook Fundamentals (2001) for sensible heat transfers and condensation and the Tran et al. (1996) correlation for boiling heat transfer in the evaporator (Equations 7 to 9). The heating and cooling capacities are deduced from the heat transfer coefficients.

$$
\alpha=8.4 \cdot 10^{5} \cdot\left(B o^{2} \cdot W e_{l}\right)^{0.3}\left(\frac{\rho_{l}}{\rho_{v}}\right)^{-0.4}
$$




$$
\begin{gathered}
B o=\frac{\dot{Q}}{S \cdot G \cdot \Delta h_{v}} \\
W e_{l}=\frac{G^{2} \cdot d}{\rho_{l} \cdot \sigma}
\end{gathered}
$$

The heat exchange surface of condensers and evaporators are divided into zones. Each zone is related to a fraction of the total surface of the exchanger. The evaporator has a two-phase zone for evaporation and a single-phase zone for superheating. The condenser has a single-phase zone for desuperheating, a two-phase zone for condensation and another single-phase zone for subcooling. The fundamental equations used on the zone $i$ are presented hereunder. Equation 10 corresponds to the heat transfer between the two fluids. Equations 11 and 12 give the heat flux on the refrigerant ("r" as subscript) side and on the source side ("s" as subscript).

$$
\begin{gathered}
\dot{Q}_{i}=U_{i} \cdot S_{i} \cdot L M T D_{i} \\
\dot{Q}_{i}=\left(\dot{m}_{r} \cdot \Delta h_{r}\right)_{i} \\
\dot{Q}_{i}=\left(\dot{m}_{s} \cdot C p_{s} \cdot \Delta T_{s}\right)_{i}
\end{gathered}
$$

In both heat exchangers models, the iterative calculation progresses from zone to zone from one end of the exchanger to the other. In the beginning, on each zone, outlet temperatures are set at the inlet values. Then, the calculations use the inlet and outlet temperatures and the structural parameters of the heat exchanger (hydraulic diameter, plate thickness) to determine the heat transfer coefficients, the new outlet temperatures and the heating or cooling capacity. The outlet variables of a zone are the inlet variables of the next zone. Once the calculation has reached the last zone, it starts again in the other way to the first zone. The whole calculation is iterated until the outlet temperatures of the refrigerant and the other fluid (water or air) have converged for the entire heat exchanger.

The low pressure adapts so that temperatures fit to a correct operation of the evaporator. In other words, the superheating has to correspond to the set value $(4 \mathrm{~K})$. The algorithm modifies the low pressure until convergence is achieved.

The subcooler is modelled as a condenser having only a liquid phase zone.

\section{SIMULATION RESULTS}

\subsection{Model validation}

The compressor model carried out using Trnsys software was fit to experimental results by adjusting parameter $\mathrm{c}$ of equation 1 . Figure 8 shows a good agreement between experimental and modelled values of mass flow rate. The uncertainty of this calculation is estimated at \pm $7 \%$. 


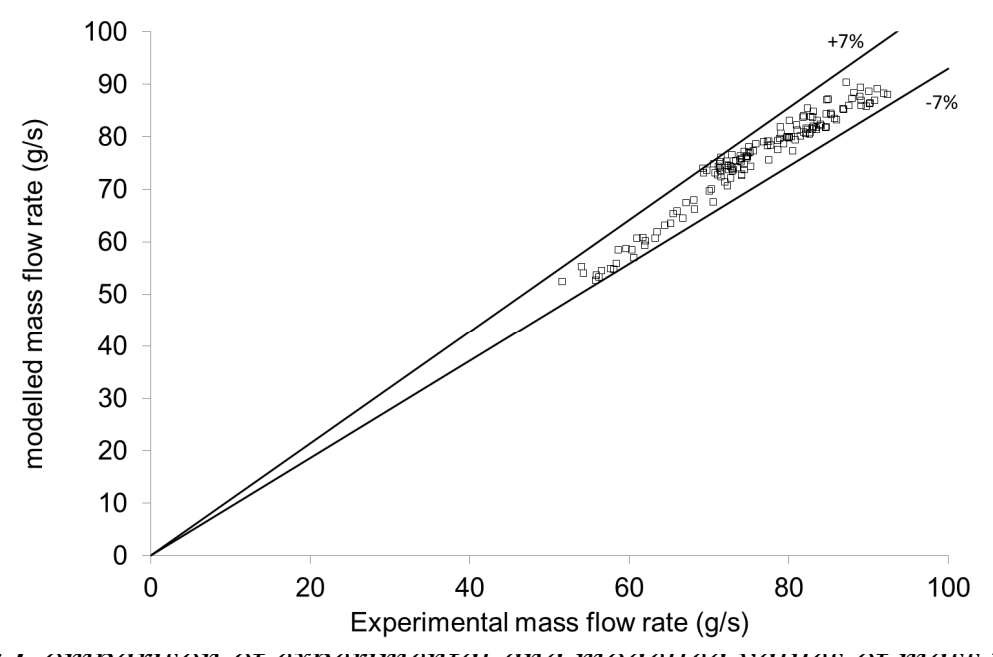

Figure 8: comparıson of experımenıа ana moaeıea vaınes oJ mass flow rate

The Trnsys model is validated in terms of electric power and thermal capacities using experimental data and results from Selection Software 7 from Emerson Copeland (2008). Figure 9 shows the comparison of electric power in a heating mode, depending on the source temperature, for two hot water inlet temperature $T_{h w \text {-in }}$ at the condenser, between our model of heat pump ("model"), the model from the manufacturer ("man") and the experimental results ("exp"). Agreement is considered satisfactory as the experimental results and the manufacturer's model results are within the uncertainty bars of 5\% applied to the homemade model. Nevertheless some improvement can still be achieved with more model development. Indeed, at a hot water temperature of $30{ }^{\circ} \mathrm{C}$, the model is systematically underestimating the experimental values.

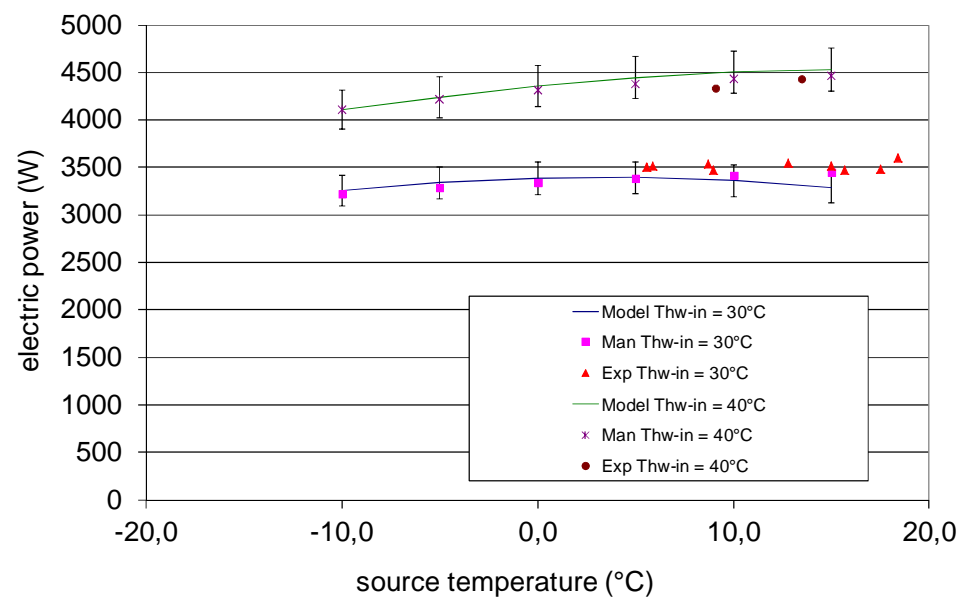

Figure 9: Comparison of electric power between models and experiments depending on source temperature

Figure 10 shows the comparison of heating capacities in a heating mode. Good agreement is achieved. As in figure 9, the uncertainty bars represent $\pm 5 \%$. The other modes have been checked and validated with an uncertainty of $5 \%$ in the more frequent source temperature range. For extreme conditions, the model is validated with an uncertainty of $10 \%$. 


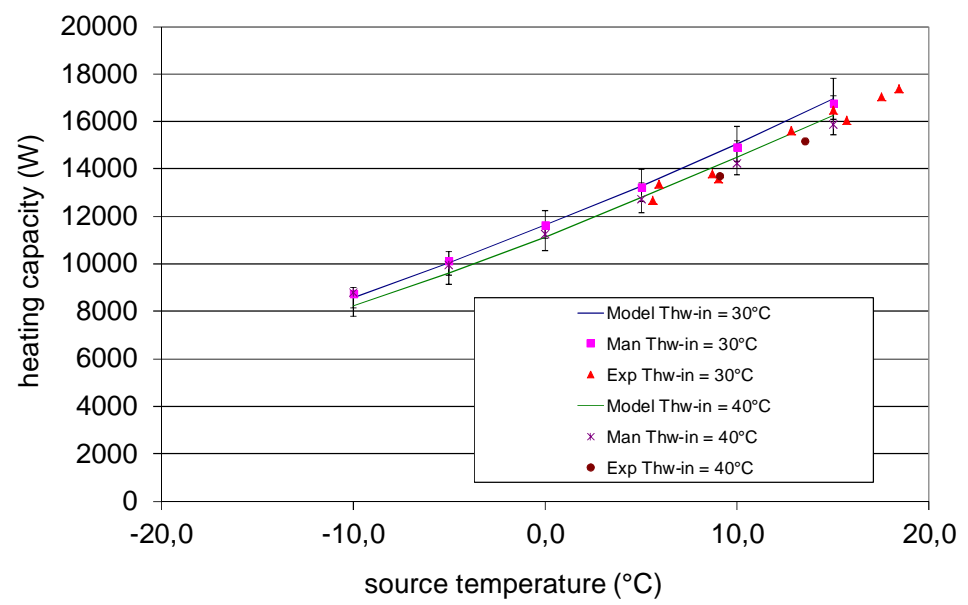

Figure 10: Comparison of heating capacities between models and experiments depending on source temperature

\subsection{Tables of performance}

For each mode, tables of input power and thermal capacities were built using the detailed heat pump models (appendixes 1 and 2). They gather the results of heating and cooling capacities and electric power for different heat source and heat sink temperatures. These tables were obtained by running the detailed heat pump models with variable source temperatures. A couple of source temperatures was set at the inlet of two heat exchangers depending on the mode of operation and the calculation was run until convergence was achieved. Then another calculation started with a second couple of source temperatures and so on over the whole range of heat source and heat sink temperatures.

Appendixes 1 and 2 show the electric power and the cooling, subcooling and heating capacities provided respectively by the HPS and a standard heat pump, on the range from - 15 to $15{ }^{\circ} \mathrm{C}$ for heat source temperatures and from 25 to $50{ }^{\circ} \mathrm{C}$ for heat sink temperatures. Cooling and simultaneous modes only work under heat source temperatures from 5 to $15{ }^{\circ} \mathrm{C}$, as the heat source is pure water. The cooling mode results are the electric power and the cooling capacity. The simultaneous mode provides also a heating capacity. In the heating mode, the results are the electric power and the heating and subcooling capacities. For a better comparison, the results are divided by the nominal heating capacity in the heating mode $\left(T_{h s o}\right.$ $=5{ }^{\circ} \mathrm{C}$ and $T_{h s i}=35^{\circ} \mathrm{C}$ ) and multiplied by a factor 10 .

The main tendencies of appendixes 1 and 2 are reported in figures 11 and 12. Independently on the mode, when the heat sink temperature decreases, the values of electric power decrease and the values of capacities increase, so COPs increase. When the heat source temperature decreases, thermal capacities also decrease whereas electric power follows a more complex trend. Indeed electric power is function of the pressure ratio and also of the low pressure. Electric power tends to decrease with the low pressure but tends to increase with a higher pressure ratio. Both trends result in a curve having a maximum for a heat source temperature around $0{ }^{\circ} \mathrm{C}$. 


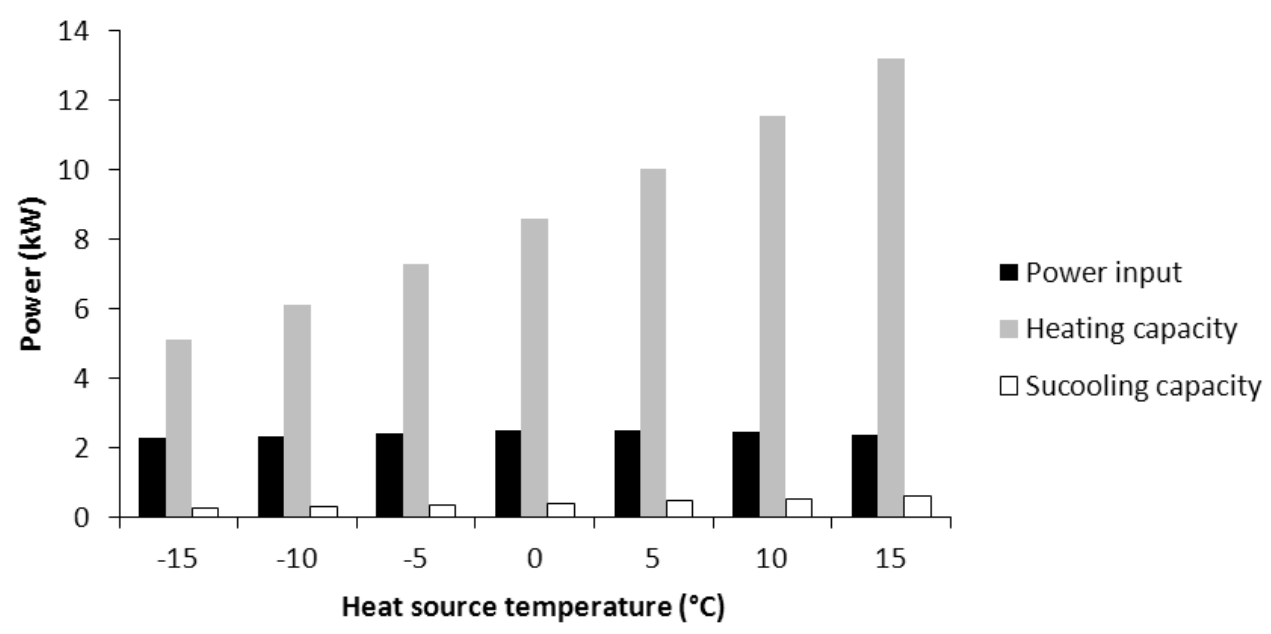

Figure 11: Evolution of power input and thermal capacities of HPS model depending on the heat source temperature for a heat sink temperature of $35^{\circ} \mathrm{C}$ (extract of appendix 1)

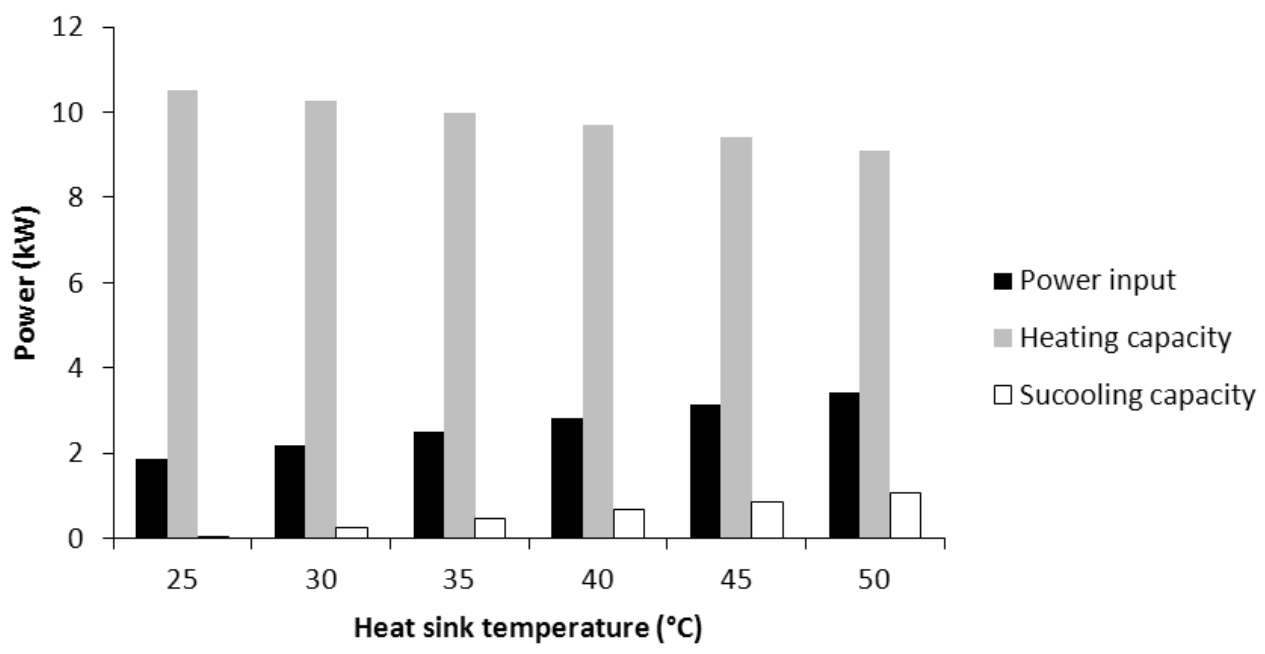

Figure 12: Evolution of power input and thermal capacities of HPS model depending on the heat sink temperature for a heat source temperature of $5^{\circ} \mathrm{C}$ (extract of appendix 1)

The HPS and the standard HP have the same values of electric powers and thermal capacities in the cooling mode because the devices are equivalent. When comparing the heating mode values, a difference due to the subcooler appears. A subcooling capacity is provided with the HPS and this increases the total heat production compared to the standard HP. The evaporator of the HPS (which is the same that the one of the standard HP) has to produce more cooling energy to compensate the increase in heat production. The evaporating pressure slightly decreases so that the temperature difference and the cooling capacity increase. Whereas there is not much difference between heating capacities, the low pressure of the HPS and the electric power are lower than that of the standard heat pump (figure 13). 


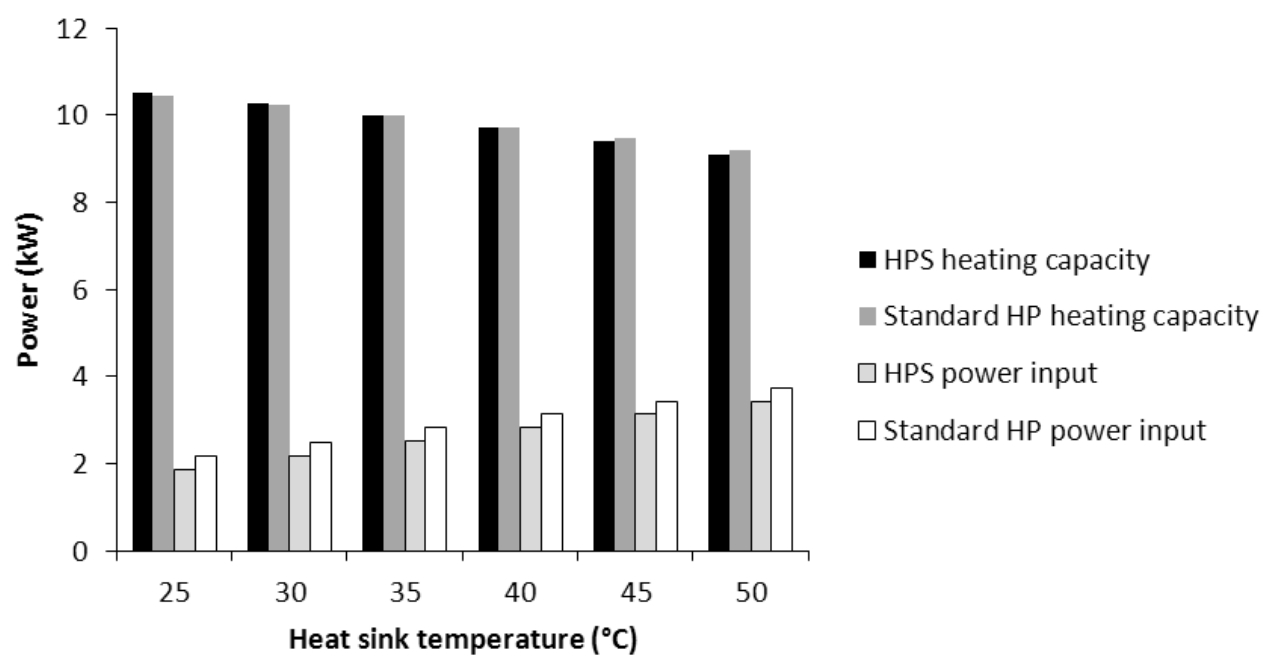

Figure 13: Evolution of heating capacity and power input of HPS and standard heat pump models depending on the heat sink temperature for a heat source temperature of $5^{\circ} \mathrm{C}$ (extract of appendix 1 and 2)

\subsection{Building consumptions}

The building annual consumptions are calculated over a representative year of each site (figure 14). Space heating and space cooling needs vary in opposite ways from the hotter to the colder climates: Marseille, Rennes and Brussels. The needs in DHW production are very high because the hotel is considered a $100 \%$ occupied every day of the year. The needs vary scarcely with the cold water network temperature.

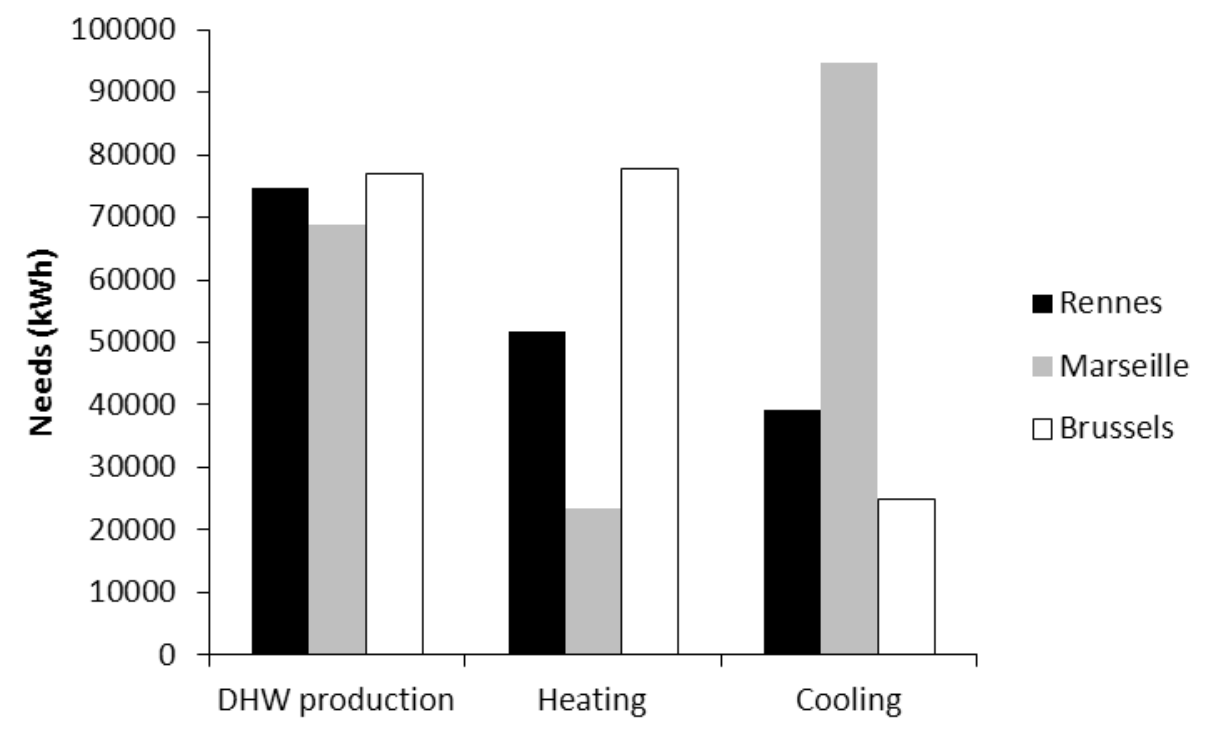

Figure 14: Needs in domestic hot water production, space heating and space cooling depending on the climate. 


\subsection{Heating and cooling system behaviour}

\subsubsection{System sizing}

In accordance with the building needs depending on the climate, the systems were sized according to the French recommendations from COSTIC (Centre d'Etudes et de Formation, Génie Climatique, Equipement Technique du Bâtiment) and AFPAC (Association Française pour les Pompes A Chaleur). The HPSs and the standard HPs were sized to provide $80 \%$ of the space heating needs at the base temperature. The electric auxiliary heater power corresponds to $40 \%$ of these needs. The colder the climate during winter, the more powerful the heat pumps. In table 2 , the heating capacity corresponds to $80 \%$ of the needs given by simulation at the base temperature. The nominal heating capacity is the interpolation of the values of appendixes 1 and 2 to fit to the base temperature value. The sizing factor is the ratio between the heating capacity and the nominal heating capacity at $T_{\text {base. }}$. This factor is applied to every value of the tables of performance (Appendixes 1 and 2) during the annual simulations.

Table 2: Sizing of the HPSs and standard HPs depending on the climate

\begin{tabular}{|c|c|c|c|c|c|c|c|}
\hline Site & Heat pump & $\begin{array}{l}\mathrm{T}_{\text {base }} \\
\left({ }^{\circ} \mathrm{C}\right)\end{array}$ & $\begin{array}{l}\text { Needs at } T_{\text {base }} \\
(\mathrm{kW})\end{array}$ & $\begin{array}{c}\text { Nominal heating } \\
\text { capacity at } \mathrm{T}_{\text {base }} \\
(\mathrm{kW})\end{array}$ & $\begin{array}{c}\text { Heating capacity } \\
\text { at } \mathrm{T}_{\text {base }} \\
(\mathrm{kW})\end{array}$ & Sizing factor & $\begin{array}{c}\text { Auxiliary heating } \\
\text { power } \\
\text { (kW) }\end{array}$ \\
\hline \multirow{2}{*}{ Rennes } & HPS & \multirow[b]{2}{*}{-4} & \multirow{2}{*}{38.11} & 7.07 & \multirow[b]{2}{*}{30.49} & 4.31 & \multirow{2}{*}{15.24} \\
\hline & Standard HP & & & 7.1 & & 4.29 & \\
\hline \multirow{2}{*}{ Marseille } & HPS & \multirow{2}{*}{-5} & \multirow{2}{*}{28.11} & 6.83 & \multirow{2}{*}{22.49} & 3.29 & \multirow{2}{*}{11.24} \\
\hline & Standard HP & & & 6.85 & & 3.28 & \\
\hline \multirow{2}{*}{ Brussels } & HPS & \multirow{2}{*}{-8} & \multirow{2}{*}{52.6} & 6.19 & \multirow{2}{*}{42.08} & 6.8 & \multirow{2}{*}{21.04} \\
\hline & Standard HP & & & 6.24 & & 6.74 & \\
\hline
\end{tabular}

In the intention of providing a fair comparison between the three climates, the sizing procedure is based on space heating. It applies well to sites where the predominant needs are in space heating. In Marseille the needs are higher in cooling and DHW production so the sizing procedure underestimates the power of heat pumps that should be installed in this site. If heat pumps were sized according to the needs in DHW and/or cooling, the electricity consumption of the auxiliary heater for DHW production would be reduced and globally, the improvement brought by the HPS compared to the standard HP would slightly increase.

\subsubsection{Electricity consumptions}

Figure 15 shows the annual electricity consumptions resulting of the simulations run with the weather data files of Rennes, Marseille and Brussels. With the HPS, the electricity savings are of course tremendous (more than $50 \%$ ) because DHW production is predominant in the energy balance and because the HPS produces an important part of that energy with a favourable COP. In the case of the standard HP, the DHW production is carried out by an electric heater. This means that when simultaneous needs in heating and cooling are important, having a device that can carry out both at the same time is very profitable. The total electricity consumption varies only slightly with the climate because what is not used for heating (in Marseille compared to Brussels for example) is consumed for cooling. 


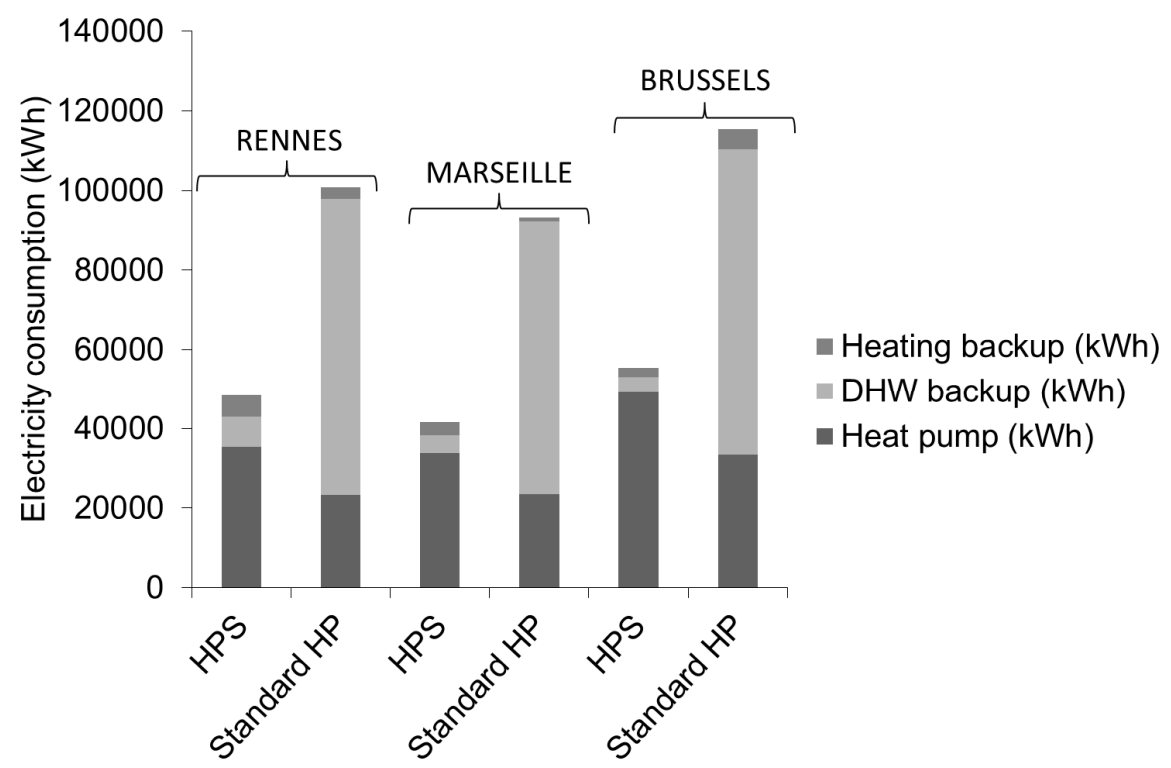

Figure 15: Electricity consumptions of the heat pumps and their backups depending on the site

Figure 16 shows the annual electricity consumptions of the HPS and the standard HP depending on the mode of operation. This decomposition presents electricity consumptions in heating and cooling modes in good correspondence with the building's needs in space heating and space cooling for both machines plus DHW production for the HPS. It reveals also that the simultaneous mode stands for a little part of the total electricity consumed by the HPS. However the simultaneous mode consumption corresponds to between $4.7 \%$ and $6.5 \%$ of the heat pump electricity consumption, it influences quite significantly the performance factors which are analysed in the next section.

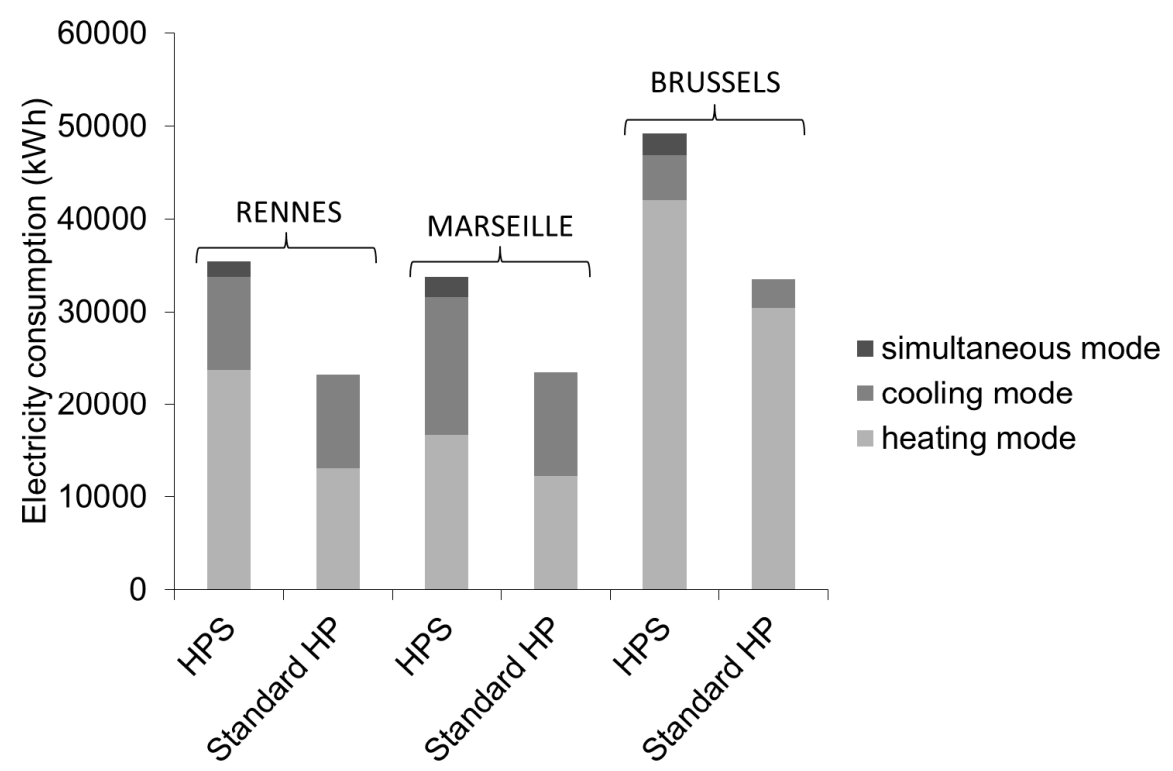

Figure 16: Electricity consumptions of the heat pumps depending on the operating mode 


\subsubsection{Performance factors}

Table 3 and figure 17 show the results of the following performance factors:

- the annual heat pump COP defined as the total useful thermal energy produced by the heat pump (only) divided by the total electric energy consumed by the heat pump (only);

- the annual system COP defined as the total useful thermal energy produced by the heat pump and the electric backups divided by the total electric energy consumed by the heat pump and the electric backups;

- the Carnot COP is the average of Carnot COPs calculated every time step weighted by the thermal energy produced during each time step;

- the exergetic efficiency is also the average exergetic efficiency weighted by the thermal energy.

Table 3 shows a clear tendency concerning the performance of the HPS compared to a standard heat pump. The annual COP is improved by $6 \%$ in Marseille, $13 \%$ in Rennes and up to $19 \%$ in Brussels. This site is the coldest of the three. Thus the system takes more benefit from the winter alternated sequence of the HPS. Carnot COP and exergetic efficiency, which are theoretical performance factors based on source temperatures, record also the highest improvement in Brussels. This means that the HPS works on average with a lower difference between source temperatures and converts better electric energy into thermal energy. In the different modes, Carnot COP and exergy efficiency calculations take into account only the heat source and the heat sink involved.

Table3: Performance factors of heat pumps depending on the site

\begin{tabular}{|cc|cccc|}
\hline Machine & Site & $\begin{array}{c}\text { COP } \\
\text { heat pump }\end{array}$ & $\begin{array}{c}\text { COP } \\
\text { system }\end{array}$ & $\begin{array}{c}\text { Carnot COP } \\
\text { heat pump }\end{array}$ & $\begin{array}{c}\text { Exergetic } \\
\text { efficiency }\end{array}$ \\
\hline HPS & Rennes & 4.34 & 3.80 & 16.22 & 0.36 \\
Standard HP & Rennes & 3.84 & 1.64 & 14.90 & 0.31 \\
\hline HPS & Marseille & 5.33 & 4.76 & 20.00 & 0.33 \\
Standard HP & Marseille & 5.02 & 1.99 & 20.64 & 0.31 \\
\hline HPS & Bruxelles & 3.61 & 3.44 & 15.33 & 0.36 \\
Standard HP & Bruxelles & 3.04 & 1.59 & 11.46 & 0.23 \\
\hline
\end{tabular}

Figure 17 presents the average coefficients of performance depending on the mode of operation per type of machine and per site. The first column corresponds to the heat pump performance without the auxiliaries. The following column shows the COP in a heating mode. The HPSs heating COPs are higher than the ones of standard HPs. This is due to the lower electric power of the HPS available in the tables of performance. On the contrary, cooling COPs are similar for both machines. The COP in the simultaneous mode is much higher in Marseille than in Rennes and Brussels. In Marseille the simultaneous mode is used in majority for cooling and DHW production whereas in the other sites, this mode is run in majority during winter sequences. In the first case, the heating and cooling capacities are useful energies that count in the COP calculation. During winter sequences, the cooling energy is not useful. Therefore it is not taken into account. 


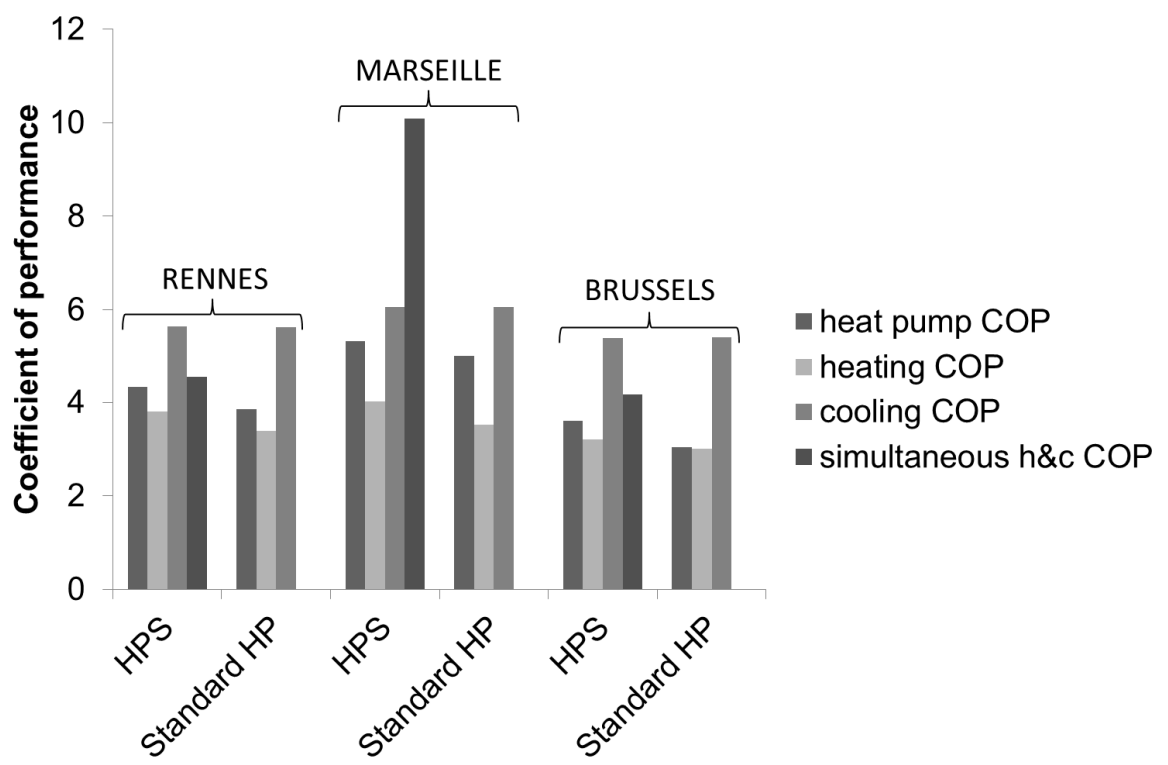

Figure 17: Coefficients of performance of heat pumps depending on the operating mode

\section{CONCLUSION}

A Heat Pump for Simultaneous heating and cooling has been designed in the aim of heating and cooling small office and residential buildings and also producing domestic hot water. Running costs and greenhouse gas emissions can be diminished by using the same electric energy to produce hot and chilled water simultaneously. This machine also proposes an answer to reduce the performance loss of air-to-water heat pumps under low ambient temperatures and especially during defrosting sequences by alternation between an air evaporator and a water evaporator. Especially, it increases the average performance in heating and liberates the air evaporator to carry out defrosting without stopping the heat production.

A model has been developed under the TRNSYS environment to assess the performance improvement of a HPS compared to a standard reversible air-to-water heat pump. The model was fitted and validated by the results of experiments run on a $15 \mathrm{~kW}$ heating capacity HPS prototype. Simulations were run with three different weather data files: Rennes, Marseille and Brussels. However the model can still be improved, namely in terms of sizing procedure, it results in a fair comparison between the HPS and a standard HP. The colder climate (Brussels) took more benefit from the winter alternated sequence for performance improvement and defrosting. In that case, the HPS outperformed the standard reversible airto-water heat pump by $19 \%$ in terms of COP. The simultaneous mode played a significant role in the performance improvement in spite of the low part of electricity consumed in this mode compared to the other modes of operation. In buildings where simultaneous needs appear in a sufficient proportion like in the case described in this paper, it looks obvious to resort to heat pumps with heat recovery such as the HPS. 


\section{REFERENCES}

ASHRAE, 2001. ASHRAE Handbook Fundamentals (SI Edition), Edition of the American Society of Heating, Refrigerating and Air-Conditioning Engineers.

Blunier, B., Cirrincione, G., Hervé, Y., Miraoui, A., 2009. A new analytical and dynamical model of a scroll compressor with experimental validation, International Journal of Refrigeration 32, 874-891.

Bourke, G., Bansal, P., 2010. Energy consumption modelling of air source electric heat pump water heaters, Applied Thermal Engineering 30, 1769-1774.

Byrne, P., Miriel, J., Lenat, Y., 2009. Design and simulation of a heat pump for simultaneous heating and cooling using $\mathrm{HFC}$ or $\mathrm{CO}_{2}$ as a working fluid, International Journal of Refrigeration 32, 1711-1723.

Cuevas, C., Lebrun, J., 2009. Testing and modelling of a variable speed scroll compressor, Applied Thermal Engineering 29, 469-478.

Cuevas, C., Lebrun, J., Lemort, V., Winandy, E., 2010. Characterization of a scroll compressor under extended operating conditions, Applied Thermal Engineering 30, 605-615.

Ding, G., 2007. Recent developments in simulation techniques for vapour-compression refrigeration systems, International Journal of Refrigeration 30, 1119-1133.

Duprez, M.-E., Dumont, E., Frère, M., 2007. Modelling of reciprocating and scroll compressors, International Journal of Refrigeration 30, 873-886.

Duprez, M.-E., Dumont, E., Frère, M., 2010. Modeling of scroll compressors - Improvements, International Journal of Refrigeration 33, 721-728.

Emerson Climate Technologies, 2008. Selection Software 7.01, Copeland Brand Products.

Huang, D., Li, Q., Yuan, X., 2009. Comparison between hot-gas bypass defrosting and reverse-cycle defrosting methods on an air-to-water heat pump, Applied Energy 86, 16971703.

Kinab, E., Marchio, D., Rivière, P., Zoughaib A., 2010. Reversible heat pump model for seasonal performance optimization, Energy and Buildings 42, 2269-2280.

Liu, D., Zhao, F.-Y., Tang, G.-F., 2007. Frosting of heat pump with recovery facility, Renewable Energy 32, 1228-1242.

Negrão, C.O.R., Erthal, R.H., Andrade, D.E.V., Wasnievski da Silva, L., 2011. A semiempirical model for the unsteady-state simulation of reciprocating compressors for household refrigeration applications, Applied Thermal Engineering 31, 1114-1124.

Refprop, 2002. Reference fluid thermodynamic and transport properties, NIST Standard Reference Database 23, Version 7.0, Copyright. 
Solar Energy Laboratory, University of Wisconsin-Madison, 2000. TRNSYS, A Transient Simulation Program, Reference Manual Volume I.

Stabat, P., 2008. IEA ECBCS Annex 48 Subtask 1: Analysis of heating and cooling demands and equipment performances, Annex 48 project report.

Sun, S., Zhao, Y., Li, L., Shu, P., 2010. Simulation research on scroll refrigeration compressor with external cooling, International Journal of Refrigeration 33, 897-906.

Tran T. N., Wambsganss M. W., France D. M., 1996. Small Circular and RectangularChannel Boiling with Two Refrigerants, International Journal of Multiphase Flow 22, 485498.

Tseng, C.-H., Chang, Y.-C., 2006. Family design of scroll compressors with optimization, Applied Thermal Engineering 26, 1074-1086.

Winandy, E., Saavedra, C., Lebrun, J., 2002. Experimental analysis and simplified modelling of a hermetic scroll refrigeration compressor, Applied Thermal Engineering 22, 107-102.

Winandy, E., Lebrun, J., 2002. Scroll compressors using gas and liquid injection: experimental analysis and modelling, International Journal of Refrigeration 25, 1143-1156. 

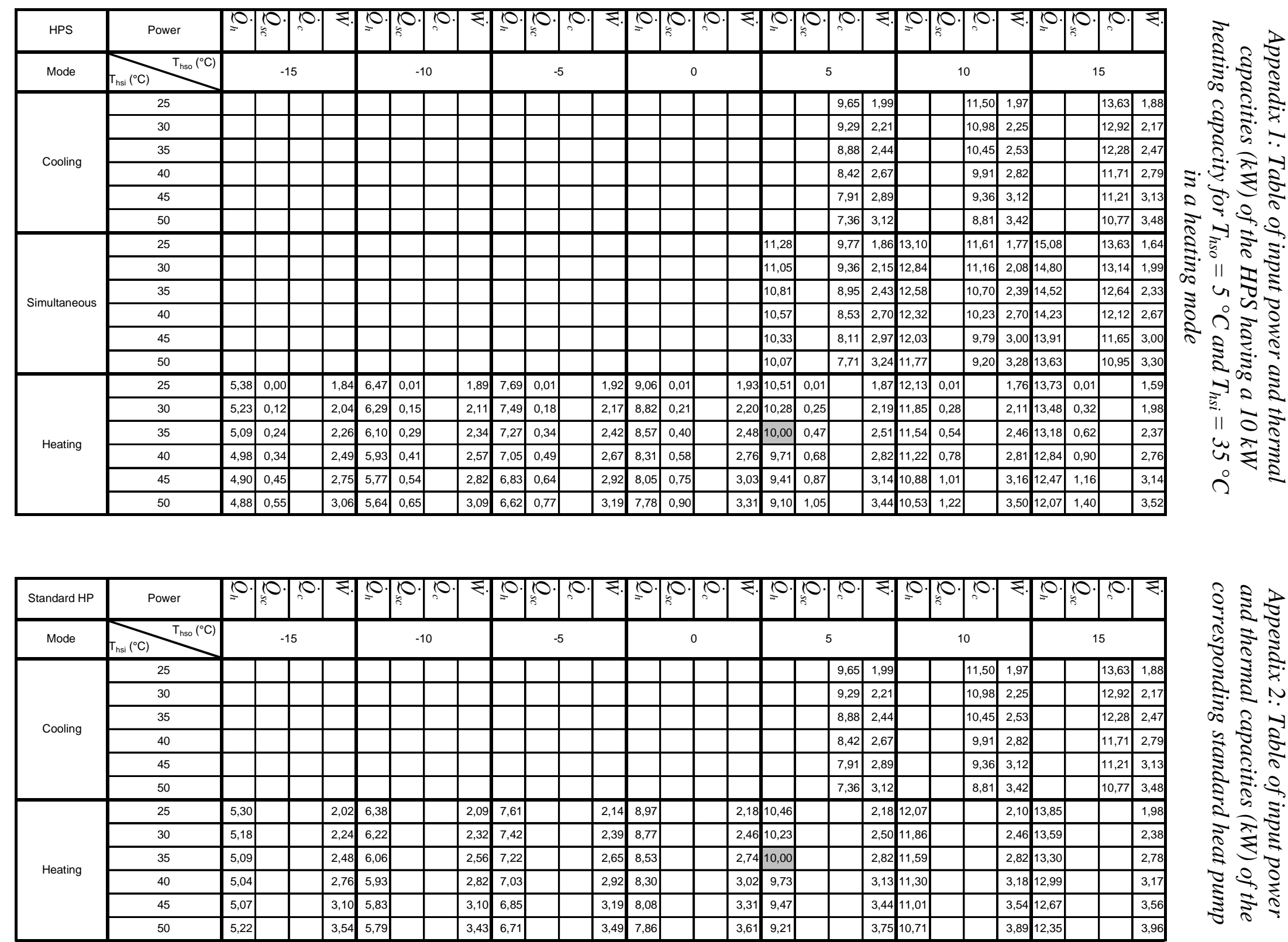
